\title{
Aa. VV., «XVII siècle», janvier-mars, janvier-mars, juillet-septembre, octobre-décembre
}

\section{Daniela Dalla Valle}

\section{OpenEdition}

\section{Journals}

\section{Edizione digitale}

URL: http://journals.openedition.org/studifrancesi/8886

DOI: 10.4000/studifrancesi.8886

ISSN: 2421-5856

\section{Editore}

Rosenberg \& Sellier

\section{Edizione cartacea}

Data di pubblicazione: 1 octobre 2008

Paginazione: 445-446

ISSN: 0039-2944

\section{Notizia bibliografica digitale}

Daniela Dalla Valle, «Aa. VV., «xvıl siècle», janvier-mars, janvier-mars, juillet-septembre, octobre-

décembre», Studi Francesi [Online], 155 (LII | II) | 2008, online dal 30 novembre 2015, consultato il 09

janvier 2021. URL: http://journals.openedition.org/studifrancesi/8886 ; DOI: https://doi.org/10.4000/ studifrancesi.8886

Questo documento è stato generato automaticamente il 9 janvier 2021.

\section{(c) (i) () $\Theta$}

Studi Francesi è distribuita con Licenza Creative Commons Attribuzione - Non commerciale - Non opere derivate 4.0 Internazionale. 


\title{
Aa. Vv., «XVII siècle», janvier-mars, janvier-mars, juillet-septembre, octobre-décembre
}

\author{
Daniela Dalla Valle
}

\section{NOTIZIA}

«XVII ${ }^{e}$ siècle», 2006

1 Segnaliamo la composizione dei quattro fascicoli del 2006, ed elenchiamo i titoli degli articoli, prevalentemente letterari, ma talvolta orientati verso la storia o la filosofia.

«XVII ${ }^{\mathrm{e}}$ siècle», janvier-mars 2006, 230, pp. 189.

4 Il volume comprende gli Atti di una giornata di studio su L'Eglise et la peinture dans la France du xviie siècle: les écrits d'ecclésiastiques, entre théologie et théorie de l'art, seguito da un settore «Varia».

5 Interessanti non solo per i letterati, ma anche per gli specialisti della critica d'arte, sono le comunicazioni inserite negli Atti: segnaliamo almeno i titoli di tutti gl'interventi: A. LE PAS DE SÉCHEVAL, Réflexions sur des termes méconnus. Quels enjeux pour l'histoire de l'art?; F. cousinIÉ, Images et contemplations dans le discours mystique du xvii ${ }^{e}$ siècle français; F. TRÉMOLIÈRES, L'art sacré au prisme de Fénelon; C. GUÉMY, Un traité de peinture manuscrit resté inédit: «La Seconde Nature» du frère carme Sébastien de Saint-Aignan; E. HÉNIN, Le décorum de l'image sacré. Une interprétation française?; S. TROUVÉ, Les écrits de Molinier, Pader et Vendanges de Malapeire et la peinture religieuse à Toulouse au xvii siècle; M. COJANNOT-LE BLANC, Les traités d'ecclésiastiques sur la perspective en France au xviie siècle.

6 Nei «Varia» è inserita una comunicazione di argomento storico-teologico (S.-M. MORGAIN, Une grande oeuvre théologique de Richelieu: La méthode la plus facile et la plus assurée pour convertir ceux qui se sont séparés de l'Eglise) e una dedicata a ricostruire la vita 
e la carriera di un artista dedito alla messa in scena teatrale (M. BAYARD, Les faiseurs d'artifices: Georges Buffequin et les artistes de l'éphémère à l'époque de Richelieu). Seguono le recensioni.

$\circ$

«XVII ${ }^{\mathrm{e}}$ siècle», avril-juin 2006, 231, pp. 193-378.

Il volume inizia con il ricordo del rimpianto Jacques Morel, scritto da Marie-Madeleine FRAGONARD. Poi esso comprende sei articoli, in parte storici e in parte letterari (M. HERSANT, Vitesse d'écriture et vérité aristocratique dans les «Mémoires» du cardinal de Retz et dans les «Mémoires» du duc de Saint-Simon; M. RUGGERI, Cioran ou la Leçon de Ténèbres des moralistes français; M. HAWCROFT, Du catholicisme des judéoconvers: Rouen 1633; P. GATULLE, La grande cabale de Gaston d'Orléans aux Pays Bas espagnols et en Lorraine; D. SÉRÉ, Mazarin et la 'comédie de Lyon'). Seguono una lunga nota su un testo relativo all'Ungheria nel Seicento e le recensioni.

"XVII ${ }^{\mathrm{e}}$ siècle», juillet-septembre 2006, 232, pp. 385-568.

Il fascicolo 232, come quello precedente, non è tematico; comprende una serie di articoli diversi, prevalentemente letterari. Segnaliamo: M. LÆRKE, À la recherche d'un homme égal à Spinoza. G.W.Leibnitz et la "Demonstratio evangelica" de Pierre-Daniel Huet; K. COGARD, Le portrait mondain, 'un nouveau genre d'écrire'. Le cas de "Divers Portraits" (1659); M. FOURNIER, La mort chrétienne d'un philosophe païen. Le fantôme de Sénèque; L. GUILLO, Un recueil de motets de Sauvaire Intermet (Avignon, c.1620-25); C. ESMEIN, La pensée du roman dans la deuxième moitié du xviie siècle; J. DE GUARDIA, Pour une poétique classique de Dom Juan; S. BERREGARD, La pratique de l'argument dans le théâtre de Tristan l'Hermite.

Nella sezione «Notes et documents» troviamo tre testi, uno bibliografico, uno prevalentemente filosofico e uno storico (E. GILBY, Les textes qui nous restent de Tallemant des Réaux; F. CHAREIX, L'archive et le système. A propos d'ouvrages philosophiques récents sur l'oeuvre de Galilée; C. WAROLIN, Armand-Jean de Mauvillain, le jeune, séminariste, docteurrégent de la Faculté de médecine de Paris.

Seguono le recensioni.

$\circ$

"XVII ${ }^{\mathrm{e}}$ siècle», octobre-décembre 2006, 233, pp. 579-763.

L'ultimo fascicolo del 2006 è dedicato alla pubblicazione della Journée d'étude du xvii ${ }^{e}$ siècle - Pierre Gassendi. Otto articoli concernono la letteratura, la filosofia, il libertinage: J.C. DARMON, Pierre Gassendi et la République des Lettres; G. PAGANINI, Le lieu du néant. Gassendi et l'hypothèse de l'annihilatio mundi'; V. JULLIEN, Gassendi, Roberval à l'académie Mersenne; I. MOREAU, Les stratégies d'écriture libertines et l'héritage gassendien: Cyrano disciple infidèle?; A. MCKEnNA, Pascal et Gassendi: la philosophie du libertin dans les "Pensées"; 0. BLOCH, Un philosophe peut-il être citoyen de la République des Lettres? Le cas Gassendi; E. BURY, Gassendi: philologie et République des Lettres; J.C. DARMON, Remarques sur la rhétorique "probabiliste" de Gassendi.

19 Seguono due articoli in Varia, uno dedicato a La Mothe le Vayer (S. GIocANTI, Scepticisme ou libertinage? Le cas de La Mothe Le Vayer), uno al mecenatismo di René de Longueil (I. LOSKоUTOFF, Le mécénat littéraire du président de Maisons). 
20 Seguono le recensioni. 